\title{
Relationship between Soil Fungi and Seedling Density in the Vicinity of Adult Conspecifics in an Arid Desert Forest
}

\author{
Yanxin Long ${ }^{1,+}$, Xiaodong Yang ${ }^{1,2,+} \mathbb{D}$, Yuee Cao ${ }^{1,3, *}$, Guanghui Lv ${ }^{1,4}$, Yan Li ${ }^{1,4}$, Yingji Pan ${ }^{5}$, Kaihong Yan ${ }^{6}$ \\ and Yanju Liu ${ }^{6}$
}

1 Institute of Resources and Environment Science, Xinjiang University, Urumqi 830046, China; Longyanxin63@163.com (Y.L.); yangxiaodong@nbu.edu.cn (X.Y.); lerlgh@sina.com (G.L.); liyan1006@xju.edu.cn (Y.L.)

2 Department of Geography \& Spatial Information Technology, Ningbo University, Ningbo 315211, China

3 School of Environmental and Geographical Science, Shanghai Normal University, Shanghai 200234, China

4 Key Laboratory of Oasis Ecology, Urumqi 830046, China

5 Institute of Environmental Sciences (CML), Leiden University, 2333 Leiden, The Netherlands; y.pan@cml.leidenuniv.nl

6 Global Centre for Environmental Remediation (GCER), The University of Newcastle (UON), Newcastle 2308, Australia; kaihong.yan@newcastle.edu.au (K.Y.); liu@newcastle.edu.au (Y.L.)

* Correspondence: caoyuee@shu.edu.cn; Tel.: +86-991-8582318

+ Those authors contributed equally.

Citation: Long, Y.; Yang, X.; Cao, Y.; Lv, G.; Li, Y.; Pan, Y.; Yan, K.; Liu, Y. Relationship between Soil Fungi and Seedling Density in the Vicinity of Adult Conspecifics in an Arid Desert Forest. Forests 2021, 12, 92. https:// doi.org/10.3390/f12010092

Received: 10 November 2020 Accepted: 12 January 2021 Published: 15 January 2021

Publisher's Note: MDPI stays neutral with regard to jurisdictional clai$\mathrm{ms}$ in published maps and institutional affiliations.

Copyright: $\odot 2021$ by the authors. Licensee MDPI, Basel, Switzerland. This article is an open access article distributed under the terms and conditions of the Creative Commons Attribution (CC BY) license (https:// creativecommons.org/licenses/by/ $4.0 /)$.

\begin{abstract}
Research Highlights: 1. Soil fungi have a higher influence on seedling density compared to soil environmental factors; 2 . Host-specific pathogens and beneficial fungi affect seeding density via different influencing mechanisms. Background and Objectives: The growth and development of seedlings are the key processes that affect forest regeneration and maintain community dynamics. However, the influencing factors of seedling growth around their adult conspecifics are not clear in arid desert forests. Probing the intrinsic relations among soil fungi, soil environmental factors ( $\mathrm{pH}$, water content, salinity, and nutrition), and seedling density will improve our understanding of forest development and provide a theoretical basis for forest management and protection. Materials and Methods: Four experimental plot types, depending on the distance to adult conspecifics, were set in an arid desert forest. Soil environmental factors, the diversity and composition of the soil fungal community, and the seedlings' density and height were measured in the four experimental plot types, and their mutual relations were analyzed. Results: Seedling density as well as the diversity and composition of the soil fungal community varied significantly among the four plot types $(p<0.05)$. Soil environmental factors, especially soil salinity, $\mathrm{pH}$, and soil water content, had significant influences on the seedling density and diversity and composition of the soil fungal community. The contribution of soil fungi (72.61\%) to the variation in seedling density was much higher than the soil environmental factors (27.39\%). The contribution of detrimental fungi to the variation in seedling density was higher than the beneficial fungi. Conclusions: Soil fungi mostly affected the distribution of seedling density in the vicinity of adult conspecifics in an arid desert forest. The distribution of seedling density in the vicinity of adults was mainly influenced by the detrimental fungi, while the adults in the periphery area was mainly influenced by the beneficial fungi.
\end{abstract}

Keywords: pathogen fungi; $\mathrm{pH}$; plant size; seedling density; soil salinity; soil water content

\section{Introduction}

Seedling density is the key biophysical factor affecting the regeneration dynamics of forest communities [1]. However, the seedling stage is the most vulnerable in the life cycle of plants due to a high mortality rate [2]. Studies have shown that the growth and survival of seedlings are more affected by the spatial distance to their adult conspecifics [3,4]. Higher mortality was observed for seedling in the locations closer to their adult conspecifics $[3,4]$. 
One possible mechanism is the regulation of soil microorganisms, especially fungi. An adult tree increases the local abundance of soil host-specific pathogenic fungi, and thus also increase the infection probability of nearby congeneric individuals. Seedlings that are located near the propagated adult trees could be easily attacked by the fungi, resulting in a higher mortality rate [5-7].

Such an influence of soil microorganisms on seedling density has been proved in many previous studies $[3,8]$. For example, plant-related fungi reduce the recruitment of seedlings in the vicinity of adult conspecifics in temperate humid forests [8]. As such, plant pathogens play a key role in seedling settlement via their inhibiting effects on seed germination in rainforest ecosystems [3,9]. However, these obvious influences of soil fungi on seedling density were mainly found in highly structurally complex forests $[3,4,8]$, probably because a high stem density facilitates the spread of fungi and maintains the fungal abundance, thereby limiting the seedling density in the vicinity of adult conspecifics [10-12]. Previous epidemiological theories suggested that the restriction of fungi, especially host-specific pathogens, on biological survival decrease with a decrease in population density. In some case, the restriction may disappear completely $[10,11,13-15]$. In less structurally complex forests, the impacts of soil fungi on seedling survival in the vicinity of adult conspecifics are still unclear. Moreover, in contrast to host-specific pathogens, some beneficial fungi may impose the opposite effects by increasing the nutrient uptake ability of the root system, raising the seedling survival ability near adult conspecifics $[11,16,17]$. However, current studies on the relationships between soil fungi and seedling density have mostly focused on the host-specific pathogens rather than on the beneficial fungi $[4,10,18]$.

The relationship between soil fungi and seedling density also may be affected by environmental factors [12,19-21] (see the conceptual framework in Figure 1). For example, environmental factors can influence the abundance of a soil fungus in a forest community, which may in turn the affect seedling density by reducing the resistance of the plants to the fungus (Figure 1). On the other hand, environmental factors can also alter the infective ability of the fungus to the host plants, thus facilitating or inhibiting seedling survival (Figure 1) [12,19]. Examples have been reported in humid forests with high stem density [3]. Soil organic matter, total nitrogen, and total phosphorus were reported to affect the seedling density in the vicinity of adult conspecifics through the triangular framework [22,23]. However, there is lack of knowledge on whether these relationships also exist in other forest ecosystems or types, especially in the less structurally complex forests (e.g., the sparse forests in arid regions). It is possible that the areas that are favorable for adult tree survival also might be suitable for seedlings survival because they have the same environmental requirements, as indicated by some studies. However, it is mostly likely that there will be negative effects on the growth and survival of the seedlings due to host-specific pathogenic attack, resource competition, and shading after a big tree has grown in a given place. It could even cause death and thus a change in seedling density.

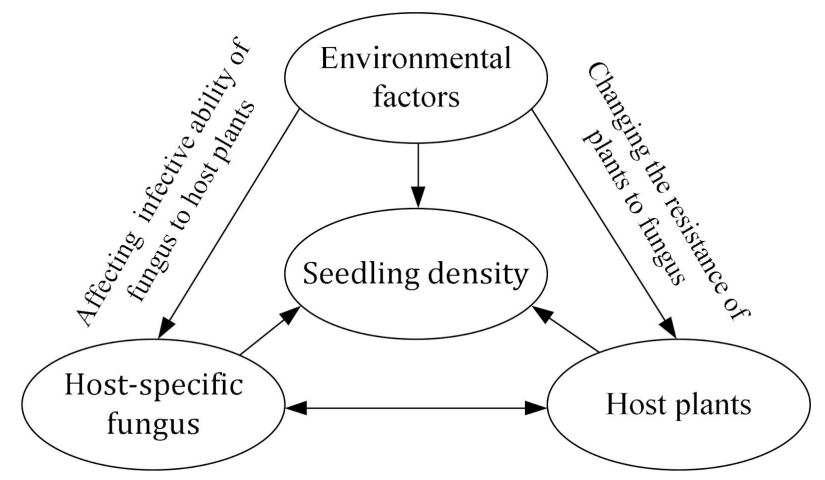

Figure 1. A conceptual framework of the triangular relationship between the host-specific fungus, soil environmental factors, and seedling density. 
Arid and semi-arid regions account for approximately one-third of the global land surface [24]. The desert forest, an especially important type of arid and semi-arid forest ecosystem, has been recognized as one of the forests experiencing the most severe ecological destruction and biodiversity loss in the past few decades $[25,26]$. Therefore, expounding the driving forces behind seedling density, especially for the seedling density of the dominant species in the arid desert forest, has been one of the major concerns for policymakers and researchers [26]. Compared with humid forests, the vegetation coverage and stem density are extremely low in arid desert, sparse forests. The relationships amongst soil fungi, environmental factors, and seedling survival in the vicinity of adult conspecifics are still unknown $[8,22,27]$. Moreover, the ecological limiting factors for plant growth in arid forests, such as soil salinity and water content, were completely different from that in humid forests, which were mainly limited by $\mathrm{pH}$ and soil nutrients [8,28].

It is still unclear whether the traditional driving factors, such as $\mathrm{pH}$, soil organic matter, and soil total nitrogen, play a role in affecting the seedling density in the vicinity of adult conspecifics in arid desert forests. In this study, Populus euphratica Oliv., a dominant species with a high abundance in arid desert forests, was selected as the model species. The composition and diversity of the soil fungal community, soil environmental factors, and community survey data of $P$. euphratica's seedlings were collected, and their relationships were analyzed. The purpose of this study is to answer the following three scientific questions regarding arid desert forest: (1) Do soil fungi affect the distribution of seedling density in the vicinity of the adult conspecifics? (2) What are the main environmental factors and fungal species impacting seedling density in the vicinity of adult conspecifics? and (3) What are the relative contributions of the soil fungi and soil environmental factors to seedling density in the vicinity of adult conspecifics? This study will provide a new perspective in explaining the mechanisms of the variance in seedling density in arid desert forests, and a theoretical basis for the management and protection of these low-stem-density forests.

\section{Materials and Methods}

\subsection{Study Site}

The study site is in the Ebinur Lake Wetland Natural Reserve, in northwest China $\left(82^{\circ} 36^{\prime}-83^{\circ} 50^{\prime} \mathrm{E}, 44^{\circ} 30^{\prime}-45^{\circ} 09^{\prime} \mathrm{N}\right)$. The site has a typical arid temperate continental climate. The mean annual precipitation is less than $100 \mathrm{~mm}$, while the annual potential evaporation ranges from 1500 to $2000 \mathrm{~mm}$. The annual average temperature ranges from 6 to $8{ }^{\circ} \mathrm{C}$. The soil belongs to the Arenosols group, with the surface salt content ranging from 4 to 8 [26]. The zonal vegetation is desert forest, which is mainly composed of drought-tolerant plants (e.g., P. euphratica, Haloxylon ammodendron C.A.Mey., Halocnemum strobilaceum Pall., Halimodendron halodendron Pall., Reaumuria soongonica Pall., Suaeda glauca Bunge, Alhagi sparsifolia Shap., and Nitraria tangutorum Bobr.). P. euphratica is a constructive species of arid desert forests. The forest canopy coverage is less than $35 \%$.

\subsection{Experimental Plot and Sample Collection}

In this study, both of the tree height and diameter at breast height (DBH) were used to classify the $P$. euphratica tree individuals into small adults (height $\leq 4.5 \mathrm{~m}, \mathrm{DBH} \leq 20 \mathrm{~cm}$ ) and big adults (height $\geq 8.5 \mathrm{~m}, \mathrm{DBH} \geq 60 \mathrm{~cm}$ ). Tree height, DBH, and crown area were measured using a Vertex meter (Vertex-IV, Haglöf Haglof, Dalarna, Sweden), tape, and a meter stick, respectively. In mid-July 2019, nine small adults and nine big adults of P. euphratica were randomly selected from a $100 \mathrm{~m} \times 100 \mathrm{~m}$ long-term experimental field (approximately 20 years) in a natural P. euphratica forest. The distance among these selected individuals was greater than $15 \mathrm{~m}$. Based on the distance from the trunk, one ringed plot $\left(\mathrm{DB}_{\text {near }}, 3 \mathrm{~m}\right.$ in radius$)$ and one cambered plot $\left(\mathrm{DB}_{\mathrm{far}}\right.$, inside and outside radius were $3 \mathrm{~m}$ and $6 \mathrm{~m}$, respectively) were established around each big adult (Figure 2). There was only one ringed plot established around the small tree with a radius of $3 \mathrm{~m}\left(\mathrm{DS}_{\text {near }}\right)$. The control was set as a circular plot of $3 \mathrm{~m}$ in radius without adults, and was at least $9 \mathrm{~m}$ away from 
both the small and big adults (Figure 2). In total, four plot types were selected in this study: $\mathrm{DB}_{\text {near }}, \mathrm{DB}_{\text {far }}$, Control, and $\mathrm{DS}_{\text {near }}$. Each treatment had nine repeated plots. All plot areas were set as $28.26 \mathrm{~m}^{2}$ in order to remove the bias of different sampling areas (Figure 2).

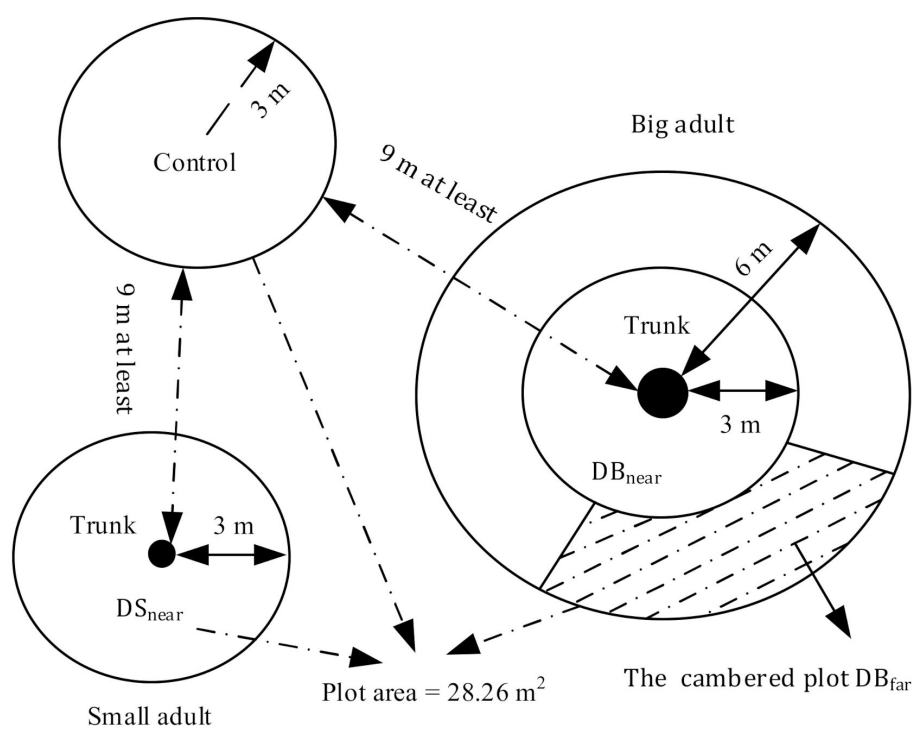

Figure 2. A schematic diagram of the sampling site design.

In each plot, the density, height, basal diameter, and crown area of the P. euphratica seedlings were surveyed. Three small and three big trees were randomly selected from the previous experimental individuals as further studied objects. Five soil samples $(0-20 \mathrm{~cm}$ depth) were randomly collected using a core sampler (301.66, AMS, Inc., Vista, CA, USA) in each plot to determine the soil physicochemical properties, soil fungal diversity, and community composition. The inner diameter of the soil cores was $2.50 \mathrm{~cm}$. The core sampler was sterilized by ethanol (75\%) before collecting the soil sample. To reduce the bias of spatial heterogeneity in microbial diversity and physicochemical property analyses, five soil samples were mixed into one composite sample for each plot. Thus, each treatment (i.e., $\mathrm{DB}_{\text {near }}, \mathrm{DB}_{\mathrm{far}}, \mathrm{DS}_{\text {near, }}$ and Control) included composited soil samples in triplicate. Finally, the mixed soil sample was divided into two parts. One part was packed in a Ziplock plastic bag and brought back to the Plant Physiology Laboratory of Xinjiang University to measure the soil physicochemical properties. Another part of the soil was placed into a $5 \mathrm{~mL}$ sterile freezing tube, and then brought to the Noah Source Gene Sequencing Company in Beijing, China, for the analyses of soil microbial diversity and community composition.

The soil water content, organic matter, bulk density, $\mathrm{pH}$, total nitrogen, and total phosphorus contents were measured using oven drying $\left(105^{\circ} \mathrm{C}\right)$, oil bath- $\mathrm{K}_{2} \mathrm{CrO}_{4}$ titration, the ring knife method, semi-micro Kjeldahl, and acid-soluble-molybdenum-antimony colorimetric methods, respectively [29,30]. Soil salinity was measured by using a conductivity meter in 1:5 (w/v) soil suspensions in deionized water (DDS-12A, Hongyi, Inc., Shanghai, China). All the physiochemical properties were measured in triplicate for each of the composited soil samples.

\subsection{Sequencing of Soil Fungal DNA}

Soil fungal DNA was extracted using the MoBio PowerSoil Extraction Kit (MoBio Laboratories, Inc., Carlsbad, CA, USA) using $0.30 \mathrm{~g}$ fresh soil according to the manufacturer's instructions. The quality of the DNA was examined using a Nanodrop ND2000 spectrophotometer (Thermo Scientific, Wilmington, DE, USA). For ITS1, the first region of the fungal ribosome gene interval, fungus-specific primers were used for PCR amplification of ITS5-1737F and ITS2-2043R. All the samples were amplified in triplicate, and no-template controls were included in all steps of the process. The PCR products were visualized using electrophoresis on $1.5 \%$ agarose gels and purified using the GeneJET Gel 
Extraction Kit (Thermo Scientific). The purified PCR amplicons products were sequenced on the Illumina HiSeq (300-bp paired-end reads) platform (Illumina Inc., San Diego, CA, USA) at the Novogene Bioinformatics Technology Co., Ltd. (Beijing, China).

The acquired sequences were filtered for quality according to the previous work of Edgar et al. [31] and Haas et al. [32]. All effective tags of the samples were clustered into the operational taxonomic units (OTUs) using UPARSE (Version 7.0.1001) based on the $97 \%$ identity of the sequences. The sequences with the highest occurrence frequency in the OTUs were selected as the representative sequences. Annotation analysis of the representative sequences was conducted using MOTHUR (Version 1.30.1) to obtain the community composition in each taxonomic level (i.e., genus, family, order, class, and phylum). The goods coverage of the fungi reached $99.9 \%$, indicating that most of the soil fungi were captured in the DNA sequence.

\subsection{Statistical Analysis}

One-way ANOVA was used to analyze the differences in seedling density, soil fungal diversity (Shannon Wiener index), and soil physicochemical properties. In the one-way ANOVA, the least-square mean separation with Duncan's correction was used to test the differences among the four treatments, if the variance of the above indicators was homogeneous. Otherwise, if the variance was heterogeneous, Tamhane's T3 test was used to test the differences.

The soil fungi's Shannon-Wiener index was calculated using QIIME 1.8.0 software based on a normalized database of OTUs [33]. At the same time, clustering analysis and analysis of similarities (ANOSIM) were used to test the differences in the composition of the soil fungi community among the four treatments. Rose Plot was used to explore the relationships between the soil environmental factors and the composition of the soil fungal community. Linear regression and hierarchical partitioning analysis were used to analyze the contributions of the soil environmental factors and soil fungi to the P. euphratica seedling density. More specifically, linear regression was first used to analyze the relationship of each soil environmental factor or each fungal abundance with the P. euphratica seedling density. If a given influencing factor has a significant linear correlation with seedling density, then this factor affects seedling density and was considered as an independent variable. The hierarchical partitioning analysis was used to test the contribution of all the independent variables to the changes in seedling density. Except for the soil fungi's Shannon-Wiener index, all data analyses were conducted in R. 3.4.3 software.

\section{Results}

\subsection{Differences in Seedling Density, Height, and Fungal Community Composition among Plot Types}

P. euphratica seedling density (mean $\pm \mathrm{SD}$ ) was significantly higher in Control $(5 \pm 1)$ and $\mathrm{DS}_{\text {near }}(3 \pm 1)$ than in $\mathrm{DB}_{\text {near }}(0 \pm 0)$ and $\mathrm{DB}_{\text {far }}(1.67 \pm 1.53)(p<0.05)$ (Figure 3a). The average height of $P$. euphratica seedlings was also significantly higher in Control $(1.96 \pm 0.22 \mathrm{~m})$ and $\mathrm{DS}_{\text {near }}(1.52 \pm 0.17 \mathrm{~m})$ than in $\mathrm{DB}_{\text {near }}(0 \pm 0 \mathrm{~m})$ and $\mathrm{DB}_{\text {far }}(0.90 \pm 0.78 \mathrm{~m})$ $(p<0.05)$ (Figure 3b).

There were significant differences in the Shannon Wiener index of the soil fungal community among the four plot types $(p<0.01)$. The comparative relationships were ordered as $\mathrm{DS}_{\text {near }}>$ control $\geq \mathrm{DB}_{\text {far }} \geq \mathrm{DB}_{\text {near }}$ (Figure 3c).

Clustering analysis indicated that the 12 soil samples can be firstly divided into four groups (Figure 4a). The ANOSIM test showed that the differences between any two groups of the four plot types were significantly higher than those within the groups $(r=1, p=0.10)$ (Figure $4 \mathrm{~b}$ ). These results indicated that our soil sampling and experimental design of soil fungi were reasonable. Moreover, these results showed the compositions of the soil fungal community were different among the four plot types (Figure 4). This result can also be found in the distribution pattern of the relative abundance of the fungal species at different taxonomic levels (Figure 5 and Supplementary Materials Figures S1-S3). 


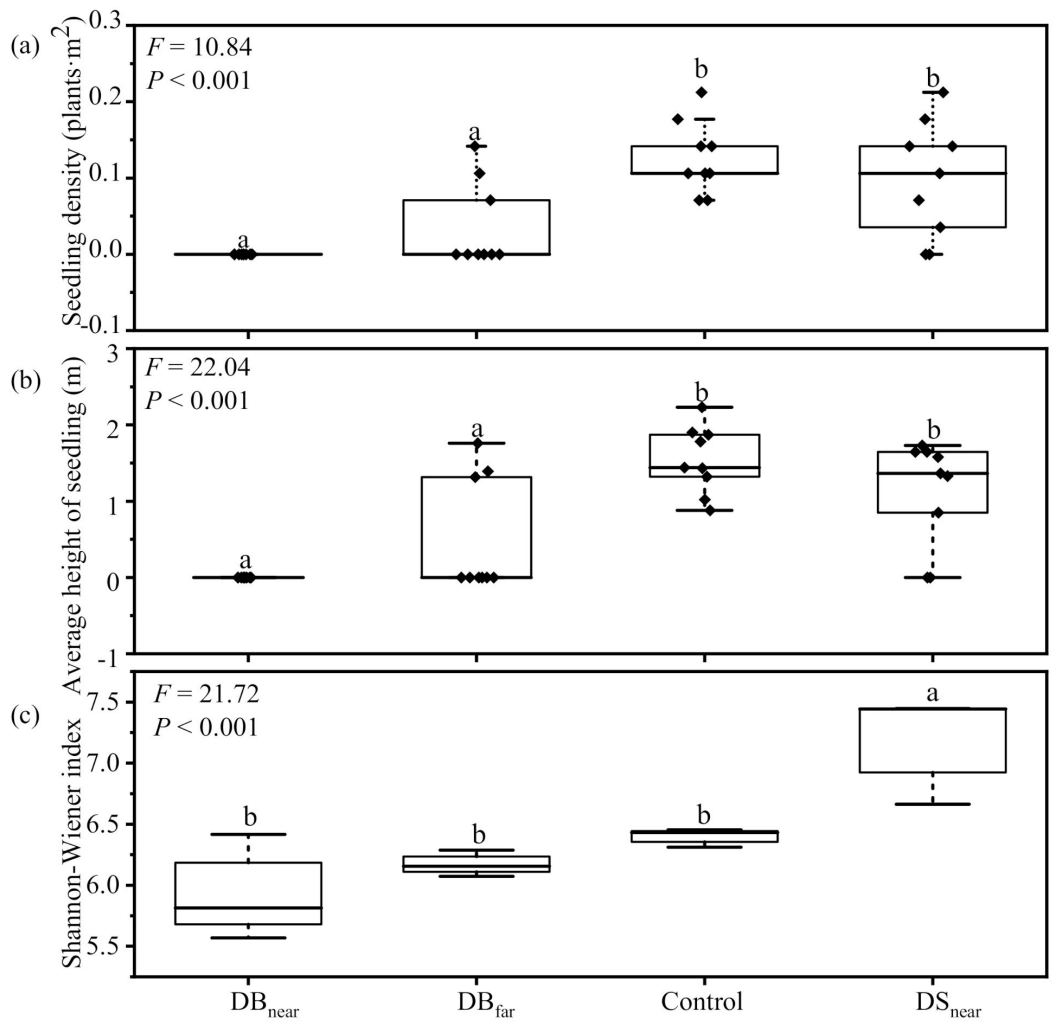

Figure 3. Differences in P. euphratica seedling density, height, and soil fungal diversity among the four plot types: (a) seedling density; (b) average seedling height; (c) soil fungal diversity. $F$ and $p$-value are the statistical results of a one-way ANOVA. $\mathrm{DB}_{\text {near }}$ and $\mathrm{DB}_{\text {far }}$ are the ringed plots and the cambered plots, and their radius around the big adults were $3 \mathrm{~m}$ and $6 \mathrm{~m}$, respectively. $\mathrm{DS}_{\text {near }}$ is the ringed plots, which were around the small adults with a radius of $3 \mathrm{~m}$. Control was the circular plots of $3 \mathrm{~m}$ in radius situated more than $9 \mathrm{~m}$ away from trunks of both the big and small adult trees.

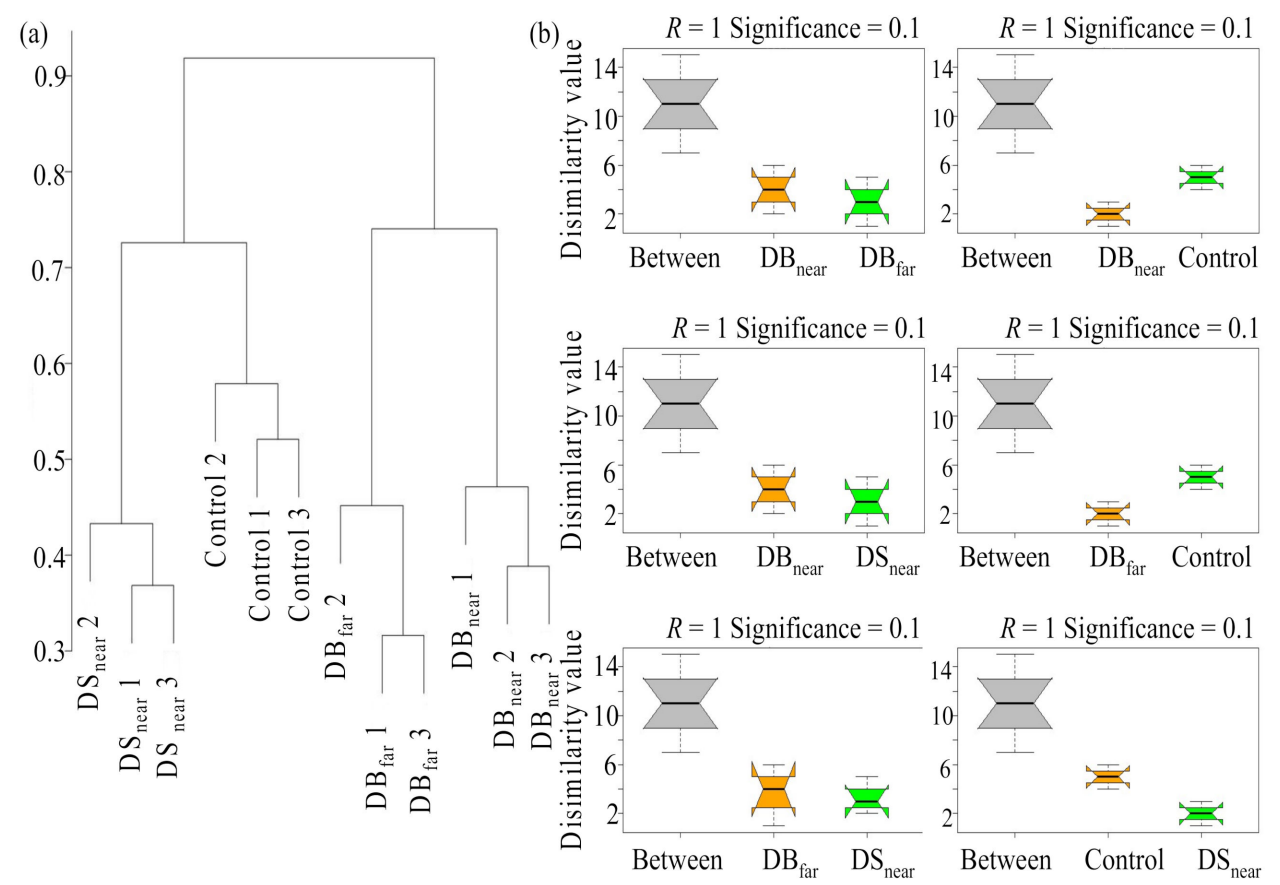

Figure 4. The clustering analysis (a) and similarities (ANOSIM) test (b) of the four fungal communities (i.e., $\mathrm{DB}_{\text {near }}, \mathrm{DB}_{\mathrm{far}}$ $\mathrm{DS}_{\text {near, }}$ and Control) based on the normalized database of OTUs. The introduction of $\mathrm{DB}_{\text {near, }}, \mathrm{DB}_{\mathrm{far}}, \mathrm{DS}_{\text {near }}$, and Control, as suggested in Figure 3. 
For example, at the phylum level, the relative abundance of Ascomycota, Basidiomycota, Mortierellomycota, Chytridiomycota, Mucoromycota, and Glomeromycota all differed among the four plot types. The relative abundances of Ascomycota were ordered as following: $\mathrm{DB}_{\text {near }}>$ Control $>\mathrm{DS}_{\text {near }}>\mathrm{DB}_{\mathrm{far}}$. Basidiomycota had a greater relative abundance in $\mathrm{DB}_{\text {near }}$ and $\mathrm{DB}_{\text {far }}$ than those in Control and $\mathrm{DS}$ near. Mortierellomycota had the highest abundance in $\mathrm{DS}_{\text {near }}$ among all plot types (Figure 5a). At the genus level, the abundance of a member of unidentified_sordariomycetes in $\mathrm{DB}_{\text {near }}$ was significantly higher than that in the other three plot types, while Russula was the highest in Control and $\mathrm{DB}_{\mathrm{far}}$. Alternaria followed the order Control $>\mathrm{DB}_{\mathrm{far}}>\mathrm{DS}_{\text {near }}>\mathrm{DB}_{\text {near }}$. Penicillium and Mortierella were both higher in $\mathrm{DS}_{\text {near }}$ than in the other three plot types (Figure $5 b$ ).

(a)

(b)

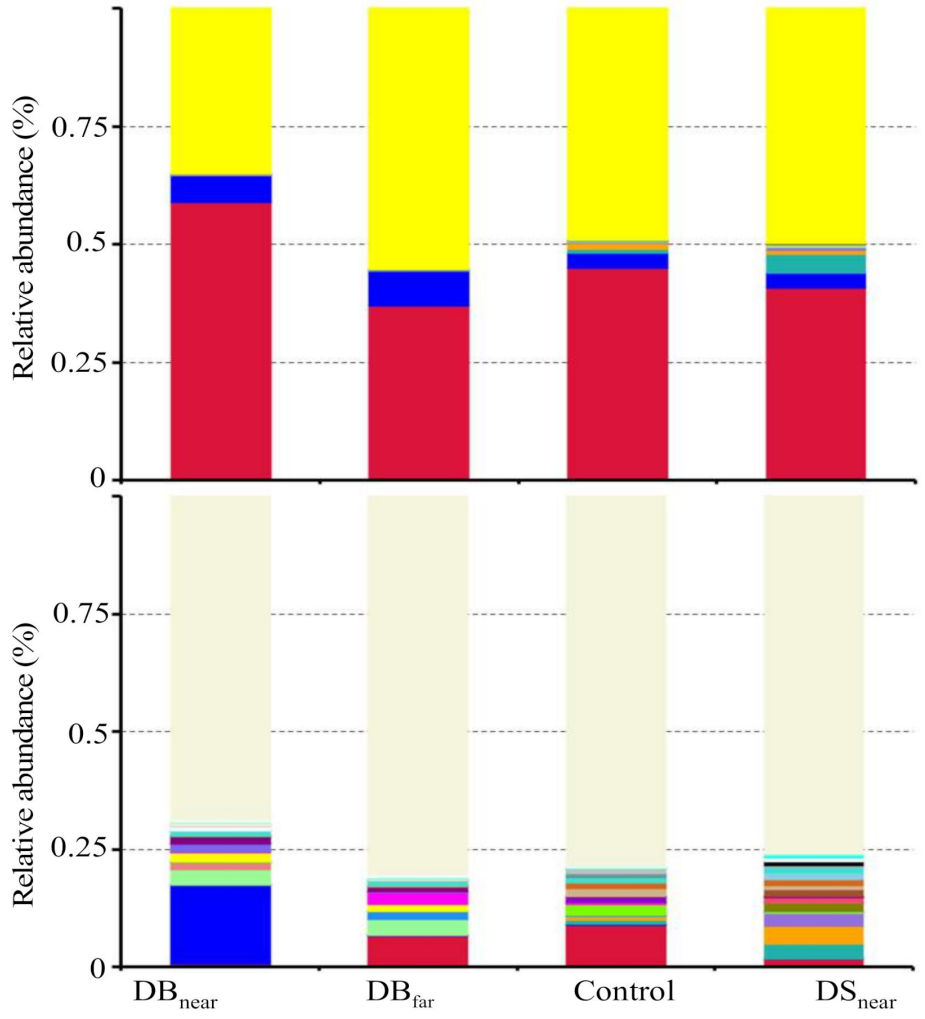

Others

- Monoblepharomycota

Olpidiomycta

Kickxellomycota

Rozellomycota

Mucoromycota

Chytridiomycota

Mortierellomycota

Basididiomycota

Ascomycota

Others

Issatchenkia

Madurella

Stachybotrys

Cunninghamella

Tricharina

Hydropisphaera

Neocamarosporium

Ulkenomyces

Aspergillus

Apororspora

Talaromyces

Engyodontium

Fusarium

Microsphaero

Kotlabaea

Acremonium

Emericellopsis

Scedosporium

Thelebolus

Monosporascus

Thielavia

Helvella

Russula

Amauroascus

Mortierella

Penicillium

unidentified_Sordariomycetes

Alternaria

Figure 5. Differences in distribution pattern of the relative abundance of soil fungi among the four plot types at the phylum and genus levels: (a) phylum; (b) genus.

Additionally, clustering analysis suggested that $\mathrm{DS}_{\text {near }}$ was combined with the control to form a group, whereas $\mathrm{DB}_{\text {near }}$ and $\mathrm{DB}_{\text {far }}$ were combined to form the other group (Figure 4a). The composition of the soil fungal community in $\mathrm{DS}_{\text {near }}$ was similar to the control, whereas that in $\mathrm{DB}_{\text {near }}$ was similar to $\mathrm{DB}_{\text {far }}$ (Figure 4a).

\subsection{Influences of Soil Environmental Factors on Soil Fungi and Seedling Density}

Except for soil bulk density and $\mathrm{pH}, \mathrm{DB}_{\text {near }}$ had the highest contents of soil water, organic matter, total nitrogen, total phosphorus, and salt salinity, followed by $\mathrm{DB}_{\mathrm{far}}$, while the lowest in Control and DS near $(p<0.05)$ (Table 1). All soil environmental factors had no significant difference between Control and $\mathrm{DS}_{\text {near }}(p>0.05)$ (Table 1). Soil water content, $\mathrm{pH}$, and salinity were significantly correlated to the seedling density $(p<0.05)$, while soil bulk density, organic matter, total nitrogen, and total phosphorus were not $(p>0.05)$ (Supplementary Materials Table S2). 
Table 1. Differences in soil environmental factors among the four plot types tested by one-way ANOVA (mean \pm SD). The different lowercase letters after the Mean values indicate a significant difference $(p<0.05)$ in soil environmental factors among the four plot types, whereas same lowercase letters show no significant differences $(p>0.05)$.

\begin{tabular}{ccccccc}
\hline Soil Environmental Factors & $\mathbf{D B}_{\text {near }}$ & $\mathbf{D B}_{\text {far }}$ & Control & DS $_{\text {near }}$ & $\boldsymbol{F}$ & $p$-Values \\
\hline Soil water content $(\%)$ & $17.0 \pm 1.32 \mathrm{a}$ & $15.9 \pm 2.07 \mathrm{~b}$ & $15.0 \pm 0.61 \mathrm{~b}$ & $14.7 \pm 0.40 \mathrm{~b}$ & 6.83 & $<0.05$ \\
Soil salinity $(\mathrm{g} / \mathrm{kg})$ & $99.7 \pm 7.80 \mathrm{a}$ & $74.8 \pm 13.6 \mathrm{~b}$ & $48.6 \pm 3.79 \mathrm{c}$ & $56.0 \pm 5.92 \mathrm{c}$ & 23.9 & $<0.01$ \\
Soil total phosphorus $(\mathrm{g} / \mathrm{kg})$ & $1.80 \pm 0.44 \mathrm{a}$ & $1.40 \pm 0.16 \mathrm{ab}$ & $1.29 \pm 0.08 \mathrm{ab}$ & $1.38 \pm 0.17 \mathrm{~b}$ & 4.20 & $<0.05$ \\
Soil organic matter $(\mathrm{g} / \mathrm{kg})$ & $28.1 \pm 17.2 \mathrm{a}$ & $6.88 \pm 3.64 \mathrm{~b}$ & $7.57 \pm 4.30 \mathrm{~b}$ & $4.82 \pm 3.15 \mathrm{~b}$ & 6.99 & $<0.05$ \\
Soil total nitrogen $(\mathrm{g} / \mathrm{kg})$ & $1.12 \pm 0.73 \mathrm{a}$ & $0.29 \pm 0.07 \mathrm{~b}$ & $0.24 \pm 0.13 \mathrm{~b}$ & $0.19 \pm 0.08 \mathrm{~b}$ & 7.34 & $<0.05$ \\
Bulk density $\left(\mathrm{g} / \mathrm{dm}^{3}\right)$ & $1.02 \pm 0.01 \mathrm{a}$ & $1.03 \pm 0.02 \mathrm{a}$ & $1.12 \pm 0.16 \mathrm{a}$ & $1.30 \mathrm{a}$ & 1.07 & $>0.05$ \\
$\mathrm{pH}$ & $8.42 \pm 0.03 \mathrm{a}$ & $8.43 \pm 0.07 \mathrm{a}$ & $8.26 \pm 0.03 \mathrm{~b}$ & $8.37 \pm 0.04 \mathrm{a}$ & 2.32 & $>0.05$ \\
\hline
\end{tabular}

The top 20 soil fungal genera, ranked according to relative abundance, were selected, and then assessed to determine the influence of the soil environmental factors. The results of the Rose Plots showed that the soil environmental factors affected the abundance of soil fungi among the four plot types (Figure 6). Specifically, organic matter, total nitrogen, total phosphorus, salinity, and $\mathrm{pH}$ significantly affected the abundances of 3, 4, 6, 8, and 5 fungal genera among the four plot types, respectively $(p<0.05)$ (Figure 6$)$. Soil bulk density had greater influences on the relative abundances of Alternaria, Engyodontium, Fusarium, Helvella, and Monosporascus than other genera (Figure 6). The variability in abundance of Helvella, Microspaeropsis and Mortierella were affected by soil water content (Figure 6).
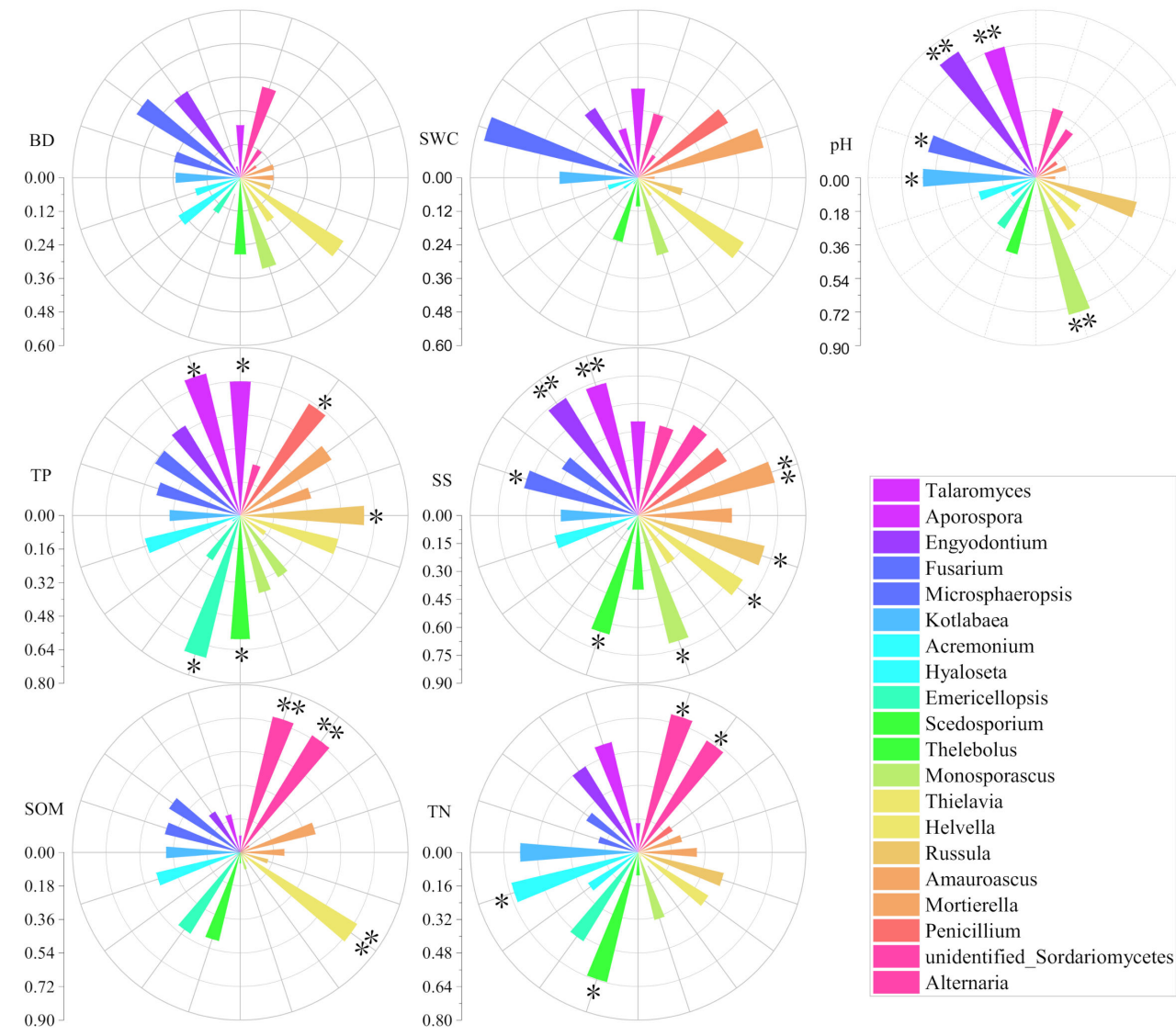

Figure 6. Rose diagrams, demonstrating the influence of the soil environmental factors on the relative abundance of soil fungi at the genus level. The longer petals indicate the greater influence of the soil environmental factors on the relative abundance of the soil fungi. BD, SWC, SS, SOM, TP, and TN are the soil bulk density, soil water content, soil salinity, soil organic matter, total phosphorus, and total nitrogen, respectively. ${ }^{*} p<0.05 .{ }^{* *} p<0.01$. 


\subsection{Contributions of the Soil Environmental Factors and Soil Fungi to the Change in Seedling Density among the Four Plot Types}

The credibility of the analytical result decreased with the increase in the number of independent variables, when the hierarchical partitioning analysis was used to calculate the relative contribution of different independent variables to the response variables. In this study, linear regression was first used to reduce the number of independent variables. A total of 10 factors, namely, soil salinity, soil water content, $\mathrm{pH}$, unidentified_Sordariomycetes, Russula, Monosporascus, Scedosporium, Acremonium, Microsphaeropsis, Engyodontium, and Aporospora, were selected as the independent variables, which were all significantly related to seedling density (Supplementary Materials Tables S1 and S2). The result of the hierarchical partitioning analysis showed that the contribution of soil fungi (the sum of 8 genera; $72.61 \%$ ) on seedling density was significantly greater than that of the soil environmental factors (the sum of soil salinity, soil water content, and $\mathrm{pH} ; 27.39 \%$ ). The $\mathrm{pH}$ had a higher contribution $(15.88 \%)$ on seedling density than soil salinity $(3.09 \%)$ and soil water content $(8.44 \%)$ (Figure 7). According to the correlation coefficient (CC) between the relative abundance of the fungi and seedling density, soil fungi can be divided into beneficial $(C C>0)$ and detrimental $(C C<0)$ fungal groups. The beneficial fungal group included Engyodontium and Apopora, while the detrimental fungal group consisted of Acremoniu, Monosporascus, Microsphaeropsis, Russula, Scedosporium, and unidentified_Sordariomycetes (Supplementary Materials Table S1). The contribution of the detrimental fungal group to seedling density $(59.88 \%)$ was higher than that of the beneficial fungal group $(12.73 \%)$. For the detrimental fungal group, the contribution followed the order Russula (27.95\%) > Monosporascus (10.59\%) > Acremonium (7.97\%) > Scedosporium (4.95\%) > Microsphaeropsis $(4.69 \%)>$ unidentified_Sordariomycetes $(3.82 \%)$. For the beneficial fungal group, the contribution of Engyodontium (6.81\%) to seedling density was higher than that of Aporospora (5.92\%) (Figure 7).

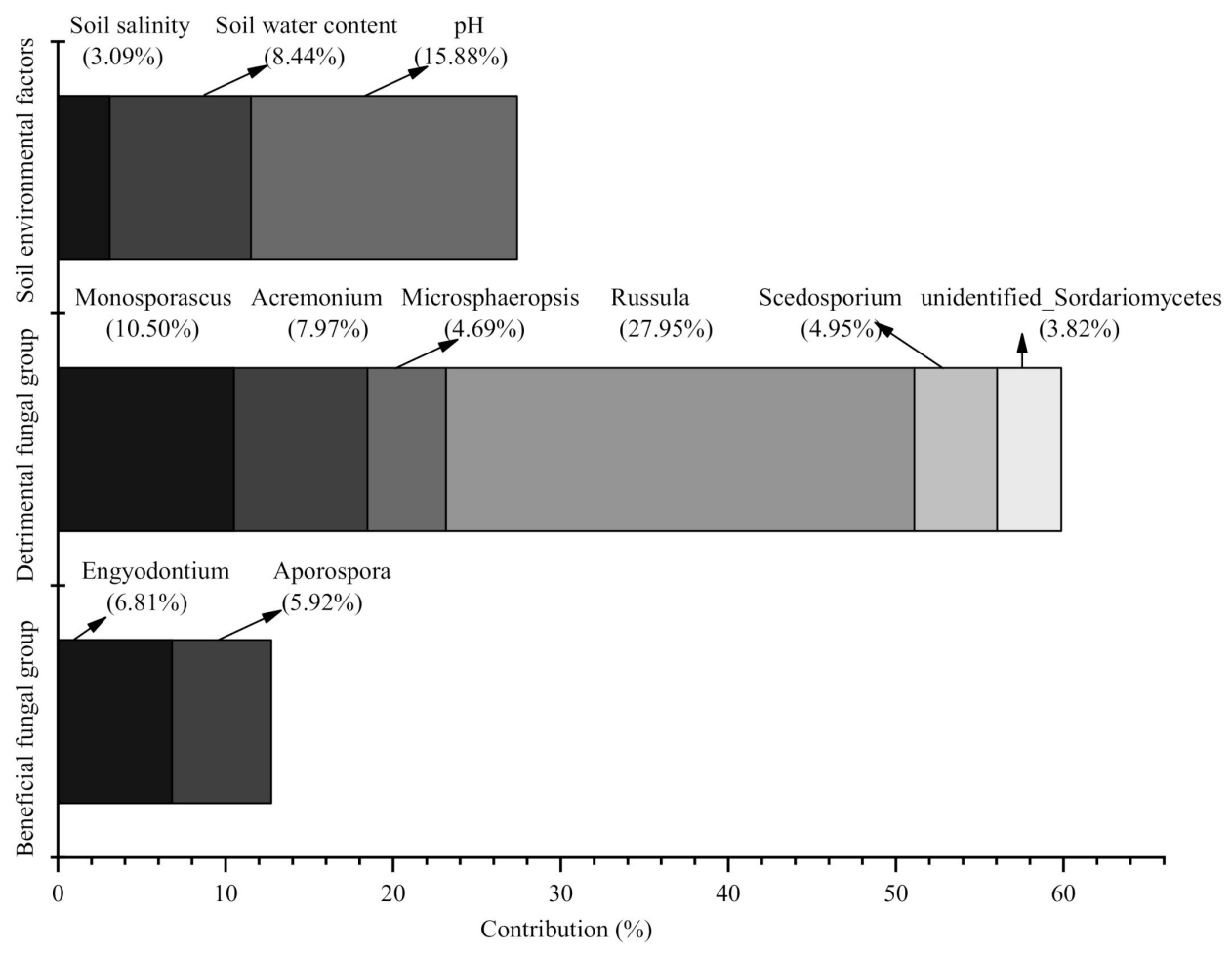

Figure 7. Contributions of the soil fungi and soil environmental factors to the change in seedling density among the four plot types. 


\section{Discussion}

\subsection{The Influence of Soil Fungi on Seedling Density near Adults of Conspecifics in Arid Desert Forest}

The density and average height of the P. euphoretic seedlings changed along with the distance to and the size of their nearby adult conspecifics (Figure 3a,b), indicating that the survival and growth of the seedlings were limited by adult conspecifics [3,4]. This result is consistent with previous studies, which indicated that seedlings had a lower density near their propagated trees due to the attack of soil fungi, especially host-specific pathogens $[3,4,34]$. Paine et al. and Comita et al. described the negative influence of hostspecific pathogens on seedling density as two ecological processes: a "distance-dependence effect" and "density-dependent effect" $[35,36]$. The first process is that the probability of a fungal attack on seedlings decreases with increasing of distance from adult conspecifics, due to the significant reduction in the quality of the host-specific pathogens in the surroundings nearby the adult trees $[18,37]$. Another process indicates that seedlings are more likely to be attacked by host-specific pathogens in areas with a high conspecific individual density than those areas with low-density. The explanation for this is that a higher density of conspecific individuals can host more pathogens, leading to more opportunities to infect seedlings [18,37]. In this study, seedling density increased along with the distance to the big adults (Control $>D_{\text {far }}>D B_{\text {near }}$ ) (Figure $3 a$ ), indicating that there was a "distancedependent effect" in the arid desert forest. Host-specific pathogens negatively affected seedling density in the vicinity of adult conspecifics. In addition, although no investigations of the change in seed bank, nor control experiments (such as seed germination and microbial inoculation) to prove the existence of a "density-dependence effect" in the arid forest in this study, the comparison in seedling density between areas around big adults and small trees can also have a similar purpose $[18,37,38]$. In the process of growth, the reproductive capacity and seed yield increased with the increase in plant size [38]. Compared to small trees, there was a higher probability of seed dispersal around the larger plants. Therefore, the density of the seeds was expected to be higher near the big adults than near the small one. It is worth knowing that our results show that the seedling density around the big adult conspecifics was significantly lower than that around small individuals ( $\mathrm{DS}_{\text {near }}>$ $\mathrm{DB}_{\text {near }}$ ) (Figure 3a), indicating that seedling survival was inversely related to the seed dispersal density. This result is in accordance with the "density-dependent effect", in that the seedling density decreased with the increase in the seed density in the vicinity of the adult conspecifics [37]. Therefore, soil fungi may play an important role in shaping the distribution of seedling density around adult conspecifics in arid desert forests.

There may also be other processes, such as resource competition, shading, and allelopathy, that affect the change in seedling density nearby the big adult conspecifics [2,39]. For example, the advantages of big trees in resource competition might cause the seedlings difficulty in obtaining enough nutrients to meet the growing demand, consequently leading to a reduced seedling density [39]. In the vicinity of the big adult trees, the shading also makes it difficult for seedlings to get sufficient sunlight for photosynthesis [40]. When the amount of photosynthetic organic matter is less than the metabolic consumption, seedlings are likely to die, resulting in a low density [40]. According to Sher et al., P. euphratica can release some secondary substances, especially for phenols, into the soil through litter and roots, which are used to restrict the growth of other individuals [41]. This process might also lead to changes in seedling density around the adult conspecifics [41]. These processes were not involved in this study; more work needs to be conducted in the future to fully reveal the mechanism of the changes in seedling density around the adult conspecifics in arid desert forests.

\subsection{The Influencing Mechanisms of Soil Fungi on Seedling Density near Adult Conspecifics in Arid Desert Forest}

The influence of soil fungi on seedling density might be attributed to their impacts on the seedling survival and seed germination in the vicinity of adult conspecifics $[3,7,11,19]$. 
With the ontogenetic development of plants, the abundance and diversity of soil fungi around the adults, especially the host-specific pathogens, increase with the adult size and decrease with the distance to the adults $[3,4,8]$. These changes would increase the influence of the host-specific pathogens on seedling survival and seed germination correspondingly, and consequently change the distribution pattern of seedling density nearby the adult conspecifics $[3,4,8,9]$. This conclusion is supported in this study as the composition and diversity of the soil fungal community changed with the four plot types (Figures 3 and 5). $\mathrm{DB}_{\text {near }}$ had a higher similarity to $\mathrm{DB}_{\text {far }}$ than to Control and $\mathrm{DS}_{\text {near }}$ regarding the composition of the soil fungal community (Figure 4).

The distribution pattern of seedling density near adult conspecifics was also affected by soil environmental factors $[11,22,42]$. As suggested by the framework of the disease triangle (Figure 1), soil environmental factors can directly affect seedling survival through nutrient supply and physiological stress $[19,22,42]$. In addition, it can indirectly affect seedling survival by altering the relationships between the soil fungus and seedlings (i.e., the tradeoffs between pathogen infectivity and plant resistance) [19,42]. The results of this study support this ecological assumption. The completely opposite change pattern among the four plot types between soil environmental factors and seedling density (soil environmental factors: $\mathrm{DB}_{\text {near }}>\mathrm{DB}_{\text {far }} \geq$ Control $\geq D S_{\text {near }}$; while seedling density is opposite) (Figure 3), indicate an obvious correlation between them. However, the magnitude of influence of the different soil environmental factors on seedling density varied. For example, seedling density was negatively correlated with soil salinity, $\mathrm{pH}$, and soil water content, while insignificantly related to soil nutrition (Table 1 ). This indicates that soil salinity, $\mathrm{pH}$, and water content may be the priority factors impacting seedling density. As the two main ecological limiting factors in this arid desert forest ecosystem, the increase in soil salinity and drought stresses can reduce seedling survival and seed germination through a change in osmotic pressure and electrolyte balance [43-45]. In addition, with the increase in these factors, the resistance of seedlings to fungal infection would be decreased, resulting in seedling death and changing the distribution pattern of seedling density $[3,8,43,44]$. The increase in $\mathrm{pH}$ would be detrimental to soil enzyme activity and nutrient absorption of plant root, thus leading to seedling death and the decline in density [46]. Oppositely, the improvement in soil nutrients, especially nitrogen and phosphorus, are beneficial for seedling density due to the facilitation of plant survival in a nutrient-poor desert ecosystem, such as arid forests $[46,47]$. In this study, the indirect influences of soil environmental factors on seedling survival can be confirmed by their correlations with the relative abundance of various soil fungi. The Rose Plot showed that soil environmental factors, especially salinity, $\mathrm{pH}$, total phosphorus, total nitrogen, and organic matter, affect the change in abundance of the majority of soil fungi among the four plot types (Figure 6). This reduced the probability of the contact between the soil fungi and seedlings, the chance of fungal infection, and altered the survival and density of the seedlings [3,8,43,44].

The results of the hierarchical partitioning analysis showed that soil fungi had higher contributions to the change in P. euphratica seedling density than soil environmental factors (Figure 7), indicating that soil fungi may play a decisive role in the density distribution of seedlings near adult conspecifics. Based on the correlation coefficients between the relative soil fungi abundance and seedling density, soil fungi can be divided into two categories: beneficial and detrimental (Supplementary Materials Table S1). The detrimental group included many host-specific pathogens that inhibit seeding growth and seed germination, while the beneficial group contained beneficial soil fungi that promote seedling growth by forming symbiotic mycorrhiza in plant root systems $[16,17,48]$. In this study, the detrimental group included the Microsphaeropsis, Monosporascus, unidentified_Sordariomycetes, Acremonium, Russula, and Scedosporium, which contributed $4.69 \%, 10.59 \%, 3.82 \%, 7.97 \%$, $27.95 \%$, and $4.95 \%$ of the variance in seedling density among four plot types, respectively (Figure 7). The Microsphaeropsis was the most influential fungus on seedling density, which may cause plant death through rotten root disease $[49,50]$. The unidentified_Sordariomycetes belonged to a genus in the Ascomycetes. Most of the fungi in the Ascomycetes have 
been confirmed as pathogenic and parasitic fungi, which are harmful to the host plants by consuming nutrients and causing plant blight [51]. Acremonium, Monosporascus, and Scedosprium are considered as the common pathogenic fungi $[52,53]$. The increase in abundance of Acremonium, Monosporascus, and Scedosprium inhibited the seedling survival and decreased the seedling density. Russula is an ectomycorrhizal fungus. It was possible to inhibit the seedling survival by forming exogenous mycorrhiza with P. euphratica to increase the spread of specific pathogens [54]. The beneficial fungus group included Engyodontium and Aporospora, which contributed $6.81 \%$ and $5.92 \%$ of the seedling density variance near the adults, respectively (Figure 7). Engyodontium is a strain of arbuscular mycorrhiza fungi, which often coexist with plant roots and improved plant nutrients and water uptake [55]. Aporospora is an endophytic fungus in the Ascomycetes [56]. Since it has the same ecological niche as the host-specific pathogens, the competition in space and nutrition may cause the Aporospora to expel the host-specific pathogens from the seedlings. Additionally, the Aporospora can also secrete antibiotics that enhance plant disease-resistance and promote plant survival [56].

Compared to species of higher relative abundance, fungi having lower relative abundance have greater effects on the distribution pattern of seedling density (Figures 5 and 7). For example, in the detrimental fungal group, the relative abundance of Russula and Monosporascus was lower than that of the unidentified_Sordariomycetes, while their contributions to the changes in seedling diversity showed the opposite pattern (Figures 5 and 7). This result was consistent with previous studies, suggesting that rare fungal species (of lower relative abundance) have a greater impact on seedling survival than common species (of higher relative abundance). This is because of the formation of the mutually restrictive triangle among fungi, soil environmental factors, and seedling survival in the long-term process of evolution $[18,19,43]$. Although common fungal species had a higher chance of contact with seedlings, their infection was also more likely to be restricted by soil environmental factors due to domestication of the environment to the pathogen fungi's pathogenicity. In contrast, rare species can be less susceptible to environmental constraints during its infection of seedlings due to their relatively low abundance [19].

The detrimental fungal group had larger contributions to the changes in seedling density than the beneficial group in the vicinity of adults (Figure 7). Additionally, the relative abundance of the soil fungi in the detrimental group decreased with the distance to the adults while it increased with adult size, whereas the beneficial group showed the opposite pattern (Figure 5). These indicate that there might be an opposite triangle relationship among seedling survival, soil environmental factors, and soil fungi [19]. In the place close to adult conspecifics, the "fertile island effect" leads to favorable soil environmental conditions in this site (such as a higher nutrient content and higher water content) $[20,21]$. At the same time, the closer distance results in a higher density of parasitic fungi from the adults $[9,11]$. The advantages of these two aspects would make it easier for harmful parasitic fungi to infect seedlings and inhibit seed germination, thus increasing seedling mortality and altering the distribution pattern of seedling density $[9,11,21]$. Here, the "island of fertility" is the phenomenon where trees act as a nutrient pump, taking up nutrients from deep soil layers and soil outside the single tree's canopy, and depositing the nutrients back under the tree canopy through litter fall or leaching $[20,57]$. On the contrary, a reduction in the influence of the "island of fertility" on nutrient enrichment causes the relatively low soil nutrient contents in places far from the adults [20,21]. Additionally, an arid forest is an ecosystem with very poor soil nutrition [26,27]. Therefore, some beneficial fungi, especially fungi that form mycorrhiza on the surface of seedling roots, can form a co-symbiosis with the seedlings' roots to reduce the limitation of a poor soil environment on seedling growth-in multiple ways, such as synthesizing the available nitrogen, expanding the uptake area of the root system, and improving the resistance of the seedling to environmental stress [17]. In this case, the beneficial fungal group affected seedling density in the places that are far from the adults. 
The influences of soil fungi on seedling density distribution indicated a similar mechanism in the plant's development. The "island of fertility" results in higher nutrients in the periphery of big trees than that of small trees (Table 1). Such differences in soil environment would make the detrimental fungal group mainly control the distribution of the seedling density around large trees, while the beneficial group dominates the changes in seedling density around the small trees. In this study, the usage of soil DNA sequencing, a community survey, and statistical analysis revealed the influence of the triangular relationships among soil fungi, soil environmental factors, and adult conspecifics on seedling density distribution in an arid desert forest. However, our results in revealing the mechanism of the distribution of seedlings around the adult conspecifics might be limited by the lack of direct evidence from controlled experiments to test the influences of the soil fungi on seedling survival and seed germination. Specifically, the fungi that were statistically responsible for seedling density were not screened and cultured from natural soils. Additionally, the direct role of the fungi in seedling survival and seed germination under the conditions of controlling the soil environmental factors were not verified by inoculation experiments. We believe further research activities are required to investigate the beneficial and detrimental influences of soil fungi on seedling survival and seed germination in arid desert forests. The results of this study, however, provided the implications of the influences of fungi on seedling density in comparison with other soil environments in natural, arid forests.

\section{Conclusions}

Our study elucidates the influences of soil fungi and soil environmental factors on the distribution of seedling density near adults of conspecifics in arid desert forests. The results showed that the soil fungi and soil environmental factors all affected the change in seedling density around the adult conspecifics. The contributions of soil fungi to the changes in seedling density was higher than that of the soil environmental factors. Based on the correlation coefficient of the relative abundance of soil fungi to seedling density, soil fungi can be divided into beneficial and detrimental fungal groups. The detrimental fungal group mainly controlled the distribution of seedling density nearer big adults, while the beneficial group mainly controlled the distribution of seedling density at a larger distance to big adults. Compared with other soil environmental factors, soil salinity, soil water content, and $\mathrm{pH}$ had higher influences on the distribution of seedling density in the vicinity of adult conspecifics, which can directly affect seedling density by physiological stress, and also indirectly affect seedling density by changing the fungal infection to plants. However, we did not use microbial inoculation experiments to verify the influences of the soil fungi, especially for the dominant fungi (e.g., Microsphaeropsis, Monosporascus, unidentified_Sordariomycetes, Acremonium, Russula, Scedosporium, Engyodontium, and Aporospora), on the seedling survival and seed germination in this arid forest. Additionally, the allelopathy, shading, and resource competition of adult trees versus seedlings might affect the distribution of seedling density; however, these aspects are not discussed in detail in this study. Further research efforts are needed to fully reveal the mechanism of the distribution of seedlings around the adult conspecifics in the future. Our study provides a new insight for explaining the reason for the seedling distribution around adult conspecifics in arid desert forests.

Supplementary Materials: The following are available online at https:/ / www.mdpi.com/1999-490 7/12/1/92/s1. Table S1. Linear regression relationships between soil fungi and seedling abundance among the four plot types; Table S2. Linear regression relationships between soil environmental factors and seedling abundance; Figure S1: Differences in distribution pattern of the relative abundance of soil fungi among four plot types at class levels; Figure S2: Differences in distribution pattern of the relative abundance of soil fungi among four plot types at order levels; Figure S3: Differences in distribution pattern of the relative abundance of soil fungi among four plot types at family levels. 
Author Contributions: Conceptualization, X.Y. and Y.C.; methodology, X.Y. and Y.L. (Yanxin Long); software, Y.L. (Yanxin Long) and X.Y.; validation, Y.L. (Yanxin Long), X.Y. and Y.C.; formal analysis, G.L. and Y.L. (Yan Li); investigation, Y.L. (Yanxin Long), Y.C. and Y.L. (Yan Li); resources, X.Y.; data curation, G.L., X.Y. and Y.C.; writing-original draft preparation, Y.L (Yanxin Long) and X.Y.; writing-review and editing, Y.L. (Yanxin Long), X.Y., Y.P., K.Y., Y.L. (Yanju Liu) and Y.L. (Yan Li); visualization, Y.L. (Yanxin Long) and Y.C.; supervision, X.Y.; project administration, X.Y.; funding acquisition, X.Y. All authors have read and agreed to the published version of the manuscript.

Funding: This work was supported by the National Natural Science Foundation of China (Grant Nos. 31860111 and 41871031), and Natural Science Foundation of Ningbo (Grant No. 202003N4133).

Acknowledgments: We are highly grateful to the anonymous reviewers and handling editor (Melantha Li) for their insightful comments, which greatly improved an earlier version of this manuscript. We thank Arshad Ali for helping us to improve the quality of the English language.

Conflicts of Interest: The authors declare no competing interest.

\section{References}

1. Messier, C.; Parent, S.; Bergeron, Y. Effects of overstory and understory vegetation on the understory light environment in mixed boreal forests. J. Veg. Sci. 1998, 9, 511-520. [CrossRef]

2. Junmeng, L.; Johnson, D.J.; Xiujuan, Q.; Zhijun, L.; Qinggang, W.; Mingxi, J. Density dependence and habitat preference shape seedling survival in a subtropical forest in central China. J. Plant Ecol. 2015, 8, 568-577.

3. Bell, T.; Freckleton, R.P.; Lewis, O.T. Plant pathogens drive density-dependent seedling mortality in a tropical tree. Ecol. Lett. 2006, 9, 569-574. [CrossRef] [PubMed]

4. Liu, Y.; Fang, S.; Chesson, P.; He, F. The effect of soil-borne pathogens depends on the abundance of host tree species. Nat. Commun. 2015, 6, 10017. [CrossRef]

5. Connell, J.H.; Tracey, J.G.; Webb, L.J. Compensatory Recruitment, Growth, and Mortality as Factors Maintaining Rain Forest Tree Diversity. Ecol. Monogr. 1984, 54, 141-164. [CrossRef]

6. Janzen, D.H. Herbivores and the Number of Tree Species in Tropical Forests. Am. Nat. 1970, 104, 501-528. [CrossRef]

7. Liu, Y.; Yu, S.; Xie, Z.P.; Staehelin, C. Analysis of a negative plant-soil feedback in a subtropical monsoon forest. J. Ecol. 2012, 100, 1019-1028. [CrossRef]

8. Jia, S.; Wang, X.; Yuan, Z.; Lin, F.; Bagchi, R. Tree species traits affect which natural enemies drive the Janzen-Connell effect in a temperate forest. Nat. Commun. 2020, 11, 286. [CrossRef]

9. Bagchi, R.; Gallery, R.E.; Gripenberg, S.; Gurr, S.J.; Narayan, L.; Addis, C.E.; Freckleton, R.P.; Lewis, O.T. Pathogens and insect herbivores drive rainforest plant diversity and composition. Nature 2014, 506, 85-88. [CrossRef]

10. Packer, A.; Clay, K. Soil pathogens and spatial patterns of seedling mortality in a temperate tree. Nature 2000, 404, $278-281$. [CrossRef]

11. Chanthorn, W.; Caughlin, T.; Dechkla, S.; Brockelman, W.Y. The Relative Importance of Fungal Infection, Conspecific Density and Environmental Heterogeneity for Seedling Survival in a Dominant Tropical Tree. Biotropica 2013, 45, 587-593. [CrossRef]

12. Mitchell, C.E.; Power, A.G. Release of invasive plants from fungal and viral pathogens. Nature 2003, 421, 625-627. [CrossRef] [PubMed]

13. Agrios, G.N. Plant Pathology, 5th ed; Elsevier Academic Press: Cambridge, MA, USA, 2005; pp. $26-27$.

14. Hirano, S.S.; Upper, C.D. Population biology and epidemiology of Pseudomonas syringae. Annu. Rev. Phytopathol. 1990, 28, 155-177. [CrossRef]

15. Antonovics, J.; Boots, M.; Ebert, D.; Koskella, B.; Poss, M. The origin of specificity by means of natural selection: Evolved and nonhost resistance in host-pathogen interactions. Evolution 2013, 67, 1-9. [CrossRef]

16. Liang, M. Arbuscular mycorrhizal fungi counteract the Janzen-Connell effect of soil pathogens. Ecology 2015, 96, 562-574. [CrossRef]

17. Sun, J.Q.; Liu, R.J.; Li, M. Advances in the study of increasing plant stress resistance and mechanisms by arbuscular mycorrhizal fungi. Plant Phys. J. 2012, 48, 845-852.

18. Zhu, K.; Woodall, C.W.; Monteiro, J.V.D.; Clark, J.S. Prevalence and strength of density-dependent tree recruitment. Ecology 2015, 96, 2319-2327. [CrossRef]

19. Liu, Y.; He, F. Incorporating the disease triangle framework for testing the effect of soil-borne pathogens on tree species diversity. Funct. Ecol. 2019, 33, 1211-1222. [CrossRef]

20. Salazar, P.C.; Navarro-Cerrillo, R.M.; Grados, N.; Cruz, G.; Barrón, V.; Villar, R. Tree size and leaf traits determine the fertility island effect in Prosopis pallida dryland forest in Northern Peru. Plant Soil 2019, 437, 117-135. [CrossRef]

21. Cai, Y.; Yan, Y.; Xu, D.; Xu, X.; Eldridge, D.J. The fertile island effect collapses under extreme overgrazing: Evidence from a shrub-encroached grassland. Plant Soil 2020, 448, 201-212. [CrossRef]

22. Mangan, S.A.; Schnitzer, S.A.; Herre, E.A.; Mack, K.M.L. Negative plant-soil feedback predicts tree-species relative abundance in a tropical forest. Nature 2010, 466, 752-755. [CrossRef] [PubMed] 
23. Mariotte, P.; Mehrabi, Z.; Bezemer, T.M.; De Deyn, G.B.; Kulmatiski, A.; Drigo, B.; Veen, G.F.; Van Der Heijden, M.; Kardol, P. Plant-Soil Feedback: Bridging Natural and Agricultural Sciences. Trends Ecol. Evol. 2017, 33, 129-142. [CrossRef] [PubMed]

24. Simpson, S.C.; Meixnera, T.; Hogan, J.F. The role of flood size and duration on streamflow and riparian groundwater composition in a semi-arid basin. J. Hydrol. 2013, 488, 126-135. [CrossRef]

25. El-Keblawy, A. Impact of Climate Change on Biodiversity Loss and Extinction of Endemic plants of Arid Land Mountains. $J$ Biodivers Endanger Species 2014, 2, 2-20. [CrossRef]

26. Yang, X.-D.; Wang, J.; Xu, M.-S.; Ali, A.; Xu, Y.; Lamb, D.; Duan, L.-C.; Yan, K.-H.; Yang, S.-T.; Bhadauria, T. Effects of the ephemeral stream on plant species diversity and distribution in an alluvial fan of arid desert region: An application of a low altitude UAV. PLoS ONE 2019, 14, e0212057. [CrossRef]

27. Bestelmeyer, B.T.; Ward, J.P.; Havstad, K.M. Soil-Geomorphic Heterogeneity Governs Patchy Vegetation Dynamics at an Arid Ecotone. Ecology 2006, 87, 963-973. [CrossRef]

28. Zeng, Y.; Zhao, C.; Shi, F.; Schneider, M.; Li, Y. Impact of groundwater depth and soil salinity on riparian plant diversity and distribution in an arid area of China. Sci. Rep. 2020, 10, 7272. [CrossRef]

29. Walkley, A.; Black, I.A. A critical examination of a rapid method for determining organic carbon in soils-effect of variations in digestion conditions and of inorganic soil constituents. Soil Sci. 1947, 63, 251-264. [CrossRef]

30. Cha, T. Soil Physicochemical Analysis; Forestry Publishing: Beijing, China, 2017.

31. Edgar, R.C. Search and clustering orders of magnitude faster than BLAST. Bioinformatics 2010, 26, 2460-2461. [CrossRef]

32. Haas, B.J.; Gevers, D.; Earl, A.M.; Feldgarden, M.; Ward, D.V.; Giannoukos, G.; Ciulla, D.; Tabbaa, D.; Highlander, S.K.; Sodergren, E. Chimeric 16S rRNA sequence formation and detection in Sanger and 454-pyrosequenced PCR amplicons. Genome Res. 2011, 21, 494-504. [CrossRef]

33. Ferrenberg, S.; Knelman, J.E.; Jones, J.M.; Beals, S.C.; Bowman, W.D.; Nemergut, D.R. Soil bacterial community structure remains stable over a 5-year chronosequence of insect-induced tree mortality. Front. Microbiol. 2014, 5, 681-691. [CrossRef] [PubMed]

34. Ramage, B.S.; Johnson, D.J.; Gonzalez-Akre, E.; Mcshea, W.J.; Anderson-Teixeira, K.J.; Bourg, N.A.; Clay, K. Sapling growth rates reveal conspecific negative density dependence in a temperate forest. Ecol. Evol. 2017, 7, 7661-7671. [CrossRef] [PubMed]

35. Paine, C.E.T.; Norden, N.; Chave, J.; Forget, P.-M.; Fortunel, C.; Dexter, K.G.; Baraloto, C. Phylogenetic density dependence and environmental filtering predict seedling mortality in a tropical forest. Ecol. Lett. 2012, 15, 34-41. [CrossRef] [PubMed]

36. Comita, L.S.; Muller-Landau, H.C.; Aguilar, S.; Hubbell, S.P. Asymmetric Density Dependence Shapes Species Abundances in a Tropical Tree Community. Science 2010, 329, 330-332. [CrossRef]

37. Comita, L.S.; Queenborough, S.A.; Murphy, S.J.; Eck, J.L.; Xu, K.; Krishnadas, M.; Beckman, N.; Zhu, Y. Testing predictions of the Janzen-Connell hypothesis: A meta-analysis of experimental evidence for distance- and density-dependent seed and seedling survival. J. Ecol. 2014, 102, 845-856. [CrossRef]

38. Augspurger, C.K.; Kitajima, K. Experimental Studies of Seedling Recruitment from Contrasting Seed Distributions. Ecology 1992, 73, 1270-1284. [CrossRef]

39. Wu, J.; Swenson, N.G.; Brown, C.; Zhang, C.; Yang, J.; Ci, X.; Li, J.; Sha, L.; Cao, M.; Lin, L. How does habitat filtering affect the detection of conspecific and phylogenetic density dependence? Ecology 2016, 97, 1182-1193. [CrossRef]

40. Cascio, C.; Schaub, M.; Novak, K.; Desotgiu, R.; Bussotti, F.; Strasser, R.J. Foliar responses to ozone of Fagus sylvatica L. seedlings grown in shaded and in full sunlight conditions. Environ. Exp. Bot. 2010, 68, 188-197. [CrossRef]

41. Sher, Z.; Hussain, F.; Ahmad, B.; Wahab, M. Allelopathic potential of Populus euphratica olivier. Pak. J. Bot. 2011, 43, 1899-1903.

42. Kardol, P.; De Deyn, G.B.; Laliberté, E.; Mariotte, P.; Hawkes, C.V.; van der Putten, W. Biotic plant-soil feedbacks across temporal scales. J. Ecol. 2013, 101, 309-315. [CrossRef]

43. Almansouri, M.; Kinet, J.M.; Lutts, S. Effect of salt and osmotic stresses on germination in durum wheat (Triticum durum Desf.) Plant Soil 2001, 231, 243-254. [CrossRef]

44. Soltani, A.; Gholipoor, M.; Zeinali, E. Seed reserve utilization and seedling growth of wheat as affected by drought and salinity. Environ. Exp. Bot. 2006, 55, 195-200. [CrossRef]

45. Barlow, K.M.; Mortensen, D.A.; Drohan, P.J. Soil pH influences patterns of plant community composition after restoration with native-based seed mixes. Restor. Ecol. 2020, 28, 869-879. [CrossRef]

46. Guan, P.; Yang, J.; Yang, Y.; Wang, W.; Wu, D. Land conversion from cropland to grassland alleviates climate warming effects on nutrient limitation: Evidence from soil enzymatic activity and stoichiometry. Glob. Ecol. Conserv. 2020, 24, e01328. [CrossRef]

47. Johnson, B.G.; Verburg, P.S.J.; Arnone, J.A. Plant species effects on soil nutrients and chemistry in arid ecological zones. Oecologia 2016, 182, 1-19. [CrossRef]

48. Gehring, C.A.; Sthultz, C.M.; Flores-Rentería, L.; Whipple, A.V.; Whitham, T.G. Tree genetics defines fungal partner communities that may confer drought tolerance. Proc. Nat. Acad. Sci. USA 2017, 114, 11169-11174. [CrossRef]

49. Bettucci, L.; Saravay, M. Endophytic fungi of Eucalyptus globulus: A preliminary study. Mycol. Res. 1993, 97, 679-682. [CrossRef]

50. Razaghi, P.; Zafari, D. First report of Microsphaeropsis Olivacea causing brown spine rot on alhagi maurorum in iran. J. Plant Pathol. 2016, 98, 369-377.

51. Harvey, R.J.; Shishkoff, N.; Pecchia, J.A.; Davis, D.D. Impact of Ammonia During Composting on Calonectria pseudonaviculata and C. henricotiae, Causal Agents of Boxwood Blight. Compost. Sci. Util. 2019, 27, 116-123. [CrossRef]

52. Guarro, J.; Gams, W.; Pujol, I.; Gené, J. Acremonium Species: New Emerging Fungal Opportunists-In Vitro Antifungal Susceptibilities and Review. Clin. Infect. Dis. 1997, 25, 1222-1229. [CrossRef] 
53. Harun, A.; Blyth, C.C.; Gilgado, F.; Middleton, P.; Chen, C.A.; Meyer, W. Development and Validation of a Multiplex PCR for Detection of Scedosporium spp. in Respiratory Tract Specimens from Patients with Cystic Fibrosis. J. Clin. Microbiol. 2011, 49, 1508-1512. [PubMed]

54. Miller, S.L.; Buyck, B. Molecular phylogeny of the genus Russula in Europe with a comparison of modern infrageneric classifications. Mycol. Res. 2002, 106, 259-276. [CrossRef]

55. Wang, W.; Li, S.; Chen, Z. Secondary Metabolites Produced by the Deep-Sea-Derived Fungus Engyodontium album. Chem. Nat. Compd. 2017, 53, 224-226. [CrossRef]

56. Brum, M.C.P.; Araújo, W.L.; Maki, C.S.; Azevedo, J.L. Endophytic fungi from Vitis labrusca L. ('Niagara Rosada') and its potential for the biological control of Fusarium oxysporum. Genet. Mol. Res. 2012, 11, 4187-4197. [CrossRef] [PubMed]

57. Ludwig, F.; De Kroon, J.C.J.M.; Berendse, F.; Prins, H.H.T. The influence of savanna trees on nutrient, water and light availability and the understorey vegetation. Plant Ecol. 2004, 170, 93-105. [CrossRef] 